\title{
The Pandemic Experience: A Corpus of Subjective Reports on Life During the First Wave of COVID-19 in the UK, Japan, and Mexico
}

\author{
Tom Froese ${ }^{1 *}$, Matthew Broome ${ }^{2}$, Havi Carel ${ }^{3}$, Clara Humpston ${ }^{2}$, Alice Malpass ${ }^{4}$, \\ Tomoari Mori ${ }^{5}$, Matthew Ratcliffe ${ }^{6}$, Jamila Rodrigues ${ }^{1}$ and Federico Sangati ${ }^{1}$ \\ 'Embodied Cognitive Science Unit, Okinawa Institute of Science and Technology Graduate University, Okinawa, Japan, \\ ${ }^{2}$ School of Psychology, University of Birmingham, Birmingham, United Kingdom, ${ }^{3}$ Department of Philosophy, University of \\ Bristol, Bristol, United Kingdom, ${ }^{4}$ Bristol Medical School, University of Bristol, Bristol, United Kingdom, ${ }^{5}$ Human Subjects \\ Research Review Committee, Okinawa Institute of Science and Technology Graduate University, Okinawa, Japan, \\ ${ }^{6}$ Department of Philosophy, University of York, York, United Kingdom
}

Keywords: COVID-19, subjective reports of experience, social distancing, corpus, cross-cultural survey

\section{BACKGROUND}

The first cases of COVID-19 were reported in Wuhan, China, in December 2019, and a month later the Emergency Safety Committee of the International Health Regulations officially declared the situation as a Public Health Emergency of International Importance. The virus quickly spread worldwide and in March 2020 was declared a pandemic. Until now, nearly two-hundred million cases of infection have been confirmed, causing nearly four million deaths. The pandemic and its consequences are having a disastrous impact on societies around the world, and this protracted global crisis is reflected in people's experience (1). Importantly, the mental health of many people across the world has been affected (2). Even in many healthy individuals feelings of fear, uncertainty, distrust, and loneliness are more common, as are raised stress and anxiety levels (3), and this situation may aggravate symptoms for those with pre-existing mental health conditions (4). Many are grieving the loss of their loved ones, and more generally a loss of meaning in life (5).

At the same time, there is also notable heterogeneity in how people have responded to this crisis; many have showed surprising levels of resilience (6), for example by turning to technology-based social interactions to compensate for lockdown restrictions (7). It is therefore crucial to combine such population-level assessments with a more individual-centered approach.

Historical archives show us that past pandemics were relatively poorly documented, but this time around there are widespread efforts to keep a detailed record (8). Our main concern, as a multidisciplinary team spanning psychology, philosophy, psychiatry, medicine, and anthropology, is that this record also includes a detailed account of how people experienced the pandemic from their own first-person perspective. We therefore decided to publicly release a cross-cultural corpus of subjective reports of the first wave of COVID-19.

There is a growing number of cross-cultural investigations of how people were impacted by the pandemic, but they usually focus on specific segments of the population and/or address very specific research questions, and often in terms of quantitative scales rather than in the form of subjective reports [e.g., (9-12)]. The value of this corpus is that it was open to all adults, and that it was intended to capture people's first-person perspective on how they experienced the pandemic impacting on various essential aspects of their everyday life. It achieved this by asking participants to describe their experiences in their own words in response to a series of thematically organized questions that were carefully crafted to facilitate this process of reflection, by 
drawing on the authors' extensive expertise in relevant areas such as phenomenological philosophy, phenomenological psychopathology, and enactive cognitive science [e.g., (13-16)].

The publicly accessible link to the online survey was distributed via the authors' social networks, news releases by their academic institutions, publications, presentations, as well as via Facebook advertising campaigns that was targeted specifically at residents in UK, Japan, and Mexico. We focused on those three countries in particular in order to capture subjective reports from participants broadly representative of the distinct sociocultural regions of Asia, Europe, and Latin America. Although COVID19 has caused a global crisis, the way countries, societies, and communities deal with the crisis is also importantly local and context-specific. For example, depending on where you live, a greeting between friends can involve different degrees of bodily contact, e.g., kissing and hugging, a handshake, or bowing, and these practices will be more or less affected by social distancing requirements.

This is not the place to provide a systematic cross-cultural comparison of these regions, so we only offer very general indications to orient the reader. According to Hofstede (17), culture in Mexico, Japan, and the UK varies along several dimensions. For example, interpersonal communication in Mexico and Japan is generally less verbally explicit, and yet decisions and activities often revolve around personal, faceto-face relationships. The UK, on the other hand, is known for the directness of communicative practices. Thus, the corpus enables researchers to investigate what are culturespecific, in contrast to culture-independent, aspects of the pandemic experience, for example by comparing Japaneselanguage participants, whose socio-cultural practices tends to be regarded as indirect, modest, and collective, with Englishlanguage participants, who are known for a more direct, goaloriented, and individualistic society.

In order to contextualize the responses of the participants, it helps to get a sense for the pandemic situation in the three representative countries during the time of data collection. According to Our World in Data (18), at the start of the survey, on June 5, 2020, the UK, Japan, and Mexico had a cumulative total of $264,150,16,958$, and 110,026 confirmed cases of COVID-19, respectively. And on that day alone the three countries reported $1,255,41$, and 3,628 new cases, as well as 170,4 , and 536 deaths due to COVID-19, respectively. In total, for the 2-month period of June 5-July 31, 2019, the UK, Japan, and Mexico reported $40,650,19,272$, and 314,614 new cases, and 2,769, 92, and 33,518 deaths, respectively.

All three countries had varying degrees of social distancing measures in place for specific regions, so a general picture is difficult to obtain. However, it seems that the severest lockdown measures that had been in operation since March 2020, were lifted around the start of the survey. For instance, in the UK in the first week of June non-essential shops were allowed to open again, albeit with social distancing in place; face masks were made mandatory the following week. In the case of Mexico, Mexico City was taken out of lockdown from mid-June onward. Japan's state of emergency was over by May 25, 2020 for all prefectures and was not reinstated for the duration of the survey. The survey therefore captures the time period when people had recently started coming out of the most severe social distancing measures, and were slowly adapting to the "new normal" of living with the pandemic under moderate restrictions.

\section{METHODS}

We ran the survey on the online platform SurveyMonkey from June 5 to July 31 2020. Participant recruitment was primarily from the authors' social media networks and Facebook, which consisted of five Facebook advertising campaigns launched in the UK, Mexico, and Japan during the survey period. The minimum age to participate in the survey was 18 .

It received 2,543 responses. Some responses did not meet the criteria for inclusion-59 participants did not grant their consent to participate, 681 participants did not fill out their name and email and hence did not proceed to the rest of the survey, and one participant was underage. Hence, 1,801 participants fulfilled the criteria, and their responses are included in the corpus. Out of the 1,801 participants that were included, 1,694 answered at least one open question. The resulting total word count for the entire corpus is 574,051 words with $2,732,007$ characters. The final breakdown of respondents by language was: 1,051 English, 507 Spanish, and 243 Japanese respondents. All responses were translated into English by professional translators, and original language responses are also included in the corpus.

It should be noted that because this was an open survey available on the Internet, overall participants were demographically more diverse, with participants from 55 different nationalities and 51 different countries of residence and with ages that spanned from 18 to 90 . However, here we focus our analysis on the specifically targeted countries of UK, Japan, and Mexico. More detailed demographic data corresponding to English, Japanese, and Spanish responses can be found in Table 1.

In order to evaluate how representative this corpus is of the overall population, it is useful to compare the self-reported demographic data of the corpus with the demographic data provided by the relevant countries. For example, in terms of gender, English-, Japanese-, and Spanish-language respondents self-identified as "female" 74,54 , and $58 \%$, respectively. In comparison, populations in the UK, Japan, and Mexico have female percentages of 51 (19), 53 (20), and 51 (21), respectively. This implies that the English-language part of the corpus has a bias toward female participants, while the Japanese- and Spanishlanguage parts are more representative. In terms of the age range, the corpus managed to capture the full range of 18-85+ years of all three countries. In addition, the median age of the English, Japanese-, and Spanish-language respondents was 53, 52, and 40 , respectively, which is consistent with median ages in the UK, Japan, and Mexico of 49,53, and 42 years, respectively (after excluding under-18-year-olds).

Given that participants were self-selected, and also free to answer as much or as little as they preferred, we cannot exclude the possibility that this has introduced other biases into the corpus. Accordingly, caution should be exercised when 
TABLE 1 | Statistics and demographics of the Pandemic Experience corpus.

\begin{tabular}{|c|c|c|c|c|}
\hline & English & Japanese & Spanish & Total \\
\hline Total responses & 1,376 & 434 & 733 & 2,543 \\
\hline Selected responses & 1,051 & 243 & 507 & 1,801 \\
\hline $\begin{array}{l}\text { Responded to at least } \\
1 \text { open-ended question }\end{array}$ & 983 & 243 & 467 & 1,693 \\
\hline Word count & 409,767 & 4,830 & 159,454 & 574,051 \\
\hline \multicolumn{5}{|l|}{ Gender } \\
\hline Male & 247 & 106 & 185 & 538 \\
\hline Female & 730 & 125 & 274 & 1,129 \\
\hline Other & 16 & 1 & 10 & 27 \\
\hline \multicolumn{5}{|l|}{ Age } \\
\hline Range & $18-87$ & $18-87$ & $18-81$ & $18-87$ \\
\hline Median & 53 & 52 & 40 & 50 \\
\hline \multicolumn{5}{|l|}{ Country of residence } \\
\hline UK & 760 & 0 & 1 & 761 \\
\hline Mexico & 19 & 0 & 424 & 443 \\
\hline Japan & 29 & 226 & 1 & 256 \\
\hline Other & 181 & 4 & 44 & 229 \\
\hline \multicolumn{5}{|l|}{ Ethnicity } \\
\hline White & 896 & 1 & 57 & 954 \\
\hline Hispanic & 28 & 1 & 373 & 402 \\
\hline Asian/Pacific Islander & 30 & 229 & 1 & 260 \\
\hline Black & 5 & 0 & 1 & 6 \\
\hline Multiple/Other & 32 & 2 & 34 & 68 \\
\hline \multicolumn{5}{|c|}{ Education (highest qualification) } \\
\hline High school & 86 & 24 & 69 & 179 \\
\hline Vocational training & 86 & 118 & 16 & 220 \\
\hline Bachelor or equivalent & 334 & 96 & 202 & 632 \\
\hline Master or equivalent & 301 & 42 & 142 & 485 \\
\hline Doctoral & 181 & 52 & 39 & 272 \\
\hline \multicolumn{5}{|l|}{ COVID-19 } \\
\hline Yes & 2 & 1 & 6 & 9 \\
\hline Suspected & 58 & 4 & 16 & 78 \\
\hline Not sure & 143 & 31 & 56 & 230 \\
\hline No & 467 & 87 & 212 & 766 \\
\hline
\end{tabular}

interpreting the corpus, especially with respect to generalizing findings to the population.

The survey consisted of six sections with a total of 42 questions (see Figure 1; the English version of the full online survey can be downloaded along with the datasets of the corpus. Participants were free to answer as many questions as they wished. Section 5 and section 6 were optional sections that dealt with more sensitive topics, and these questions were only displayed if participants confirmed their willingness to participate.

- Section 1 ("Personal characteristics") consisted of nine questions regarding the demographic data and self-described medical history of the participant.

- Section 2 ("Social experience") consisted of eight open-ended questions about social experience and two questions regarding the date of lockdown measures.
- Section 3 ("General experience") consisted of 10 open ended questions about general experiences such as the subjective experience of time and space and coping mechanisms.

- Section 4 ("Other experiences") consisted of three questions about other experiences like the occurrence of any positive changes and hopes for the future.

- Section 5 ("Illness experience") consisted of six questions related to experiences of illness.

- Section 6 ("Grief experience") consisted of four questions about the experience of grief.

\section{DATA DESCRIPTION}

The corpus is composed of five comma-separated value (CSV) files (EN.csv, JP.csv, JP2EN.csv, ES.csv, ES2EN.csv), where each row contains the answers from a single participant and each column corresponds to a particular question of the survey. Each participant is identified by a unique id which follows the convention $L L \_C C \_D D D D$ (e.g., EN_UK_0001), where $L L$ stands for language (EN, ES, JP), CC country of residence (UK, MX, JP, OO for other, NA not specified), and DDDD is an incremental number of the received response based on the starting timestamp.

This is not the place to provide an in-depth analysis of the corpus. We provide a sketch of some of the content that it contains, and which can form the basis for future research. During our initial coding of responses we took a closer look at the UK-resident participants of the corpus $(N=760)$, and we focused on several common themes. In what follows we provide overall percentages of those UK participants that had referred to a particular topic (based on word queries), along with participant IDs of some illustrative examples, including some suitable for future cross-cultural comparisons. Note that the percentages are relatively low when compared to the total number of participants, but they are best considered to represent a minimum number of participants concerned with the topic. This is because participants were not equally descriptive in their responses and they were free to answer only a subset of open questions. In other words, many participants do not get counted in the word searches simply because they did not write many words in response to questions in the first place. Still, a comparison among these percentages reveals some relative tendencies.

\subsection{Awareness of Breathing}

As might be expected, given that COVID-19 is a severe acute respiratory illness, the breath was a topic of concern for this survey. However, perhaps surprisingly, the word "breath" was used relatively rarely; only $9 \%$ of UK participants mentioned it $(N=70)$. Among those participants, some reported a higher awareness of their breathing (e.g., EN_UK_0369, EN_MX_0324). Understanding the impact of the virus in the respiratory system was regarded as important for some participants; for example, some even practiced breathing exercises as a helping measure in case of contracting COVID-19 (EN_UK_1044). Others mentioned that their breathing awareness did not change (EN_UK_1375, JP_JP_0106), for instance because it was already 


\begin{tabular}{|c|c|c|c|c|}
\hline $0: *$ Respondent ID & 12: * Your e-mail address: & $\begin{array}{l}\text { 42: If the strictest social distancing measures have } \\
\text { already been lifted in your area, around which date } \\
\text { were they lifted? }\end{array}$ & $\begin{array}{l}\text { 54: * Have you had experiences, of any kind, that } \\
\text { seemed strange or unfamiliar? If so, please try to } \\
\text { iescribe them. }\end{array}$ & $\begin{array}{l}\text { 66: * If you have been tested, did the test results } \\
\text { match your experience of symptoms, if any? }\end{array}$ \\
\hline 1: * Collector ID & 13: What is your age (in years)? & $\begin{array}{l}\text { 43: * How do you feel about social distancing? Do you } \\
\text { think it is appropriate? }\end{array}$ & $\begin{array}{l}\text { 55: * Have you had any experiences or thoughts that } \\
\text { scared or worried you? If so, in what ways? }\end{array}$ & $\begin{array}{l}67: \text { *I f you think you had Colv- } 19 \text { but are unsure, } \\
\text { were there any ysmptoms that made you think you } \\
\text { had it? And why do you have doubts? }\end{array}$ \\
\hline 2: Start Date & 14-30: How many people do you live with? & $\begin{array}{l}\text { 44: *Are any of the people in your household } \\
\text { especially vulnerablele to ill ness? If so, has this affected } \\
\text { your experience of social distancing in any way? }\end{array}$ & $\begin{array}{l}\text { 56: * Have you noticed any changes in what you eat, } \\
\text { vour exercise habits or your sleep patterns? }\end{array}$ & $\begin{array}{l}\text { 68: * Have you been more aware of your breathing? If } \\
\text { so, in what ways? }\end{array}$ \\
\hline 3: End Date & 31-32: * What is your gender? & $\begin{array}{l}45: \text { * How, if at all, has social distancing affected how } \\
\text { you experience and relate to other poople? Do the } \\
\text { people vou live with or other people seem different in } \\
\text { any way? }\end{array}$ & $\begin{array}{l}\text { 57: * Have you noticed changes in your experience of } \\
\text { time? }\end{array}$ & $\begin{array}{l}\text { 69: * Have you experienced breathlessness, even if } \\
\text { unrelated to an illness? If so, what did it ifeel like? }\end{array}$ \\
\hline 4:XIP Address & $\begin{array}{l}\text { 33: What is your nationality } \\
\end{array}$ & $\begin{array}{l}\text { 46: * How, if at all, has your ability to trust other } \\
\text { people changed in the context of the pandemic? }\end{array}$ & $\begin{array}{l}58: * \text { When ou think of the future in light of the } \\
\text { current pandemic, what do yuu think about and what } \\
\text { do you hope for? }\end{array}$ & $\begin{array}{l}\text { 70: Are you willing to answer some questions related } \\
\text { to grief? }\end{array}$ \\
\hline 5: X Email Address & $\begin{array}{l}\text { 34-35: * What is vour ethnicty? } \\
\text { lat }\end{array}$ & $\begin{array}{l}\text { 47: * Have you felt lonely or isolated? If so, how have } \\
\text { you tried to cope with this? }\end{array}$ & $\begin{array}{l}\text { 59: *Are there things that you have been doing to } \\
\text { better cope with the situation? }\end{array}$ & $\begin{array}{l}7: \text { I fou had a loved one in hospitial what was it } \\
\text { like to follow social distancing in that situation? What } \\
\text { did you do to cope? }\end{array}$ \\
\hline 6:X First Name & $\begin{array}{l}\text { 36: What is your country of residence? } \\
\text { a }\end{array}$ & 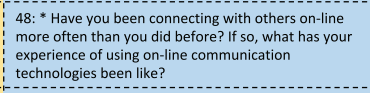 & $\begin{array}{l}\text { 60: * How has your free time changed, and how did } \\
\text { this affect vour experience of the situation? }\end{array}$ & $\begin{array}{l}\text { 72: * Has anyone close to you died due to Covio-19? If } \\
\text { so, what was vour reationship with that person or } \\
\text { those people? }\end{array}$ \\
\hline 7:X Last Name & 37 * What is your occupation or job, if any? & 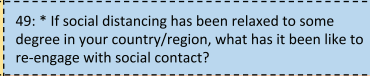 & $\begin{array}{l}61 * \text { Have you noticed any positive changes in how } \\
\text { you experience your life your relationships with } \\
\text { others, or your self? }\end{array}$ & $\begin{array}{l}\text { 73: * Has your ability to grieve for someone who has } \\
\text { died been affected by social-distancing measures? }\end{array}$ \\
\hline $8: \times$ Custom Data 1 & $\begin{array}{l}\text { 38: What is your highest educational } \\
\text { qualification? }\end{array}$ & $\begin{array}{l}\text { 50: * Has the pandemic added any uncertainty to your } \\
\text { life? If so, how has this affected you? }\end{array}$ & $\begin{array}{l}\text { 62: *ret here any important aspects of how your } \\
\text { experience has changed that we have not asked you } \\
\text { about? }\end{array}$ & \multirow{2}{*}{$\begin{array}{l}\text { 74: * Have you felt any sense of grief or loss over other } \\
\text { aspects of Ilife that have changed because of the } \\
\text { pandemic? If so, what has affected you most? }\end{array}$} \\
\hline 9: language & $\begin{array}{l}\text { 39: * can vou describe your diagnosed } \\
\text { physical and/or mental headth conditions, if } \\
\text { any? }\end{array}$ & $\begin{array}{l}\text { 51: * When you go outside, do famililar placess seem } \\
\text { different in any way? How, if atall, has the way you } \\
\text { experience the world as a whole changed? }\end{array}$ & $\begin{array}{l}\text { 63: Are you willing to answer some questions related } \\
\text { to illness? }\end{array}$ & \\
\hline 10: Agree (Informed Consent). & $\begin{array}{l}\text { 40: * What kind of social distancing measures } \\
\text { have vou been under? How restricted is your } \\
\text { contact with others at the moment? }\end{array}$ & $\begin{array}{l}\text { 52: * Have you noticed any effects on your ability to } \\
\text { think, or on what you think about? }\end{array}$ & $\begin{array}{l}\text { 64: To your knowledge, have you contracted } \\
\text { CoviD-19? }\end{array}$ & \multirow{2}{*}{$\begin{array}{l}\text { 75: Can the Principal Investigatoro of this project } \\
\text { contact vou by e-mail (at the addresss you provided at } \\
\text { the start of the survey) to invite you to a follow-up } \\
\text { study? }\end{array}$} \\
\hline 11: * Your full name: & $\begin{array}{l}\text { 41: Around which date did you start to have } \\
\text { significant reduced social contact with people } \\
\text { outside your household? }\end{array}$ & $\begin{array}{l}\text { 53: * Have you felt more anxious or calmer than usual? } \\
\text { Have your moods and emotions been affected in any } \\
\text { other ways? If so, how? }\end{array}$ & $\begin{array}{l}\text { 65: * *f a medical professional suspected or confirmed } \\
\text { that you had contracted CoviD-19, please could you } \\
\text { tell us what your experience of the illiness was like. }\end{array}$ & \\
\hline
\end{tabular}

FIGURE 1 | Summary of all the data fields of the "experiences of social distancing during the COVID-19 pandemic" online survey. Fields that are prefixed with a * allowed content that was not restricted to predetermined values. 
heightened due to regular yoga practice (EN_UK_0379) or swimming (EN_UK_0023).

\subsection{Digital Communication}

A notable proportion of participants referred to usage of online and digital communication tools. For instance, "online" was mentioned by $30 \%$ of UK participants $(N=231)$, while social media applications (including "WhatsApp," "Facebook," "Instagram," "TikTok," and "Twitter") were mentioned by $10 \%$ $(N=78)$, and videoconferencing applications (including "Zoom," "Skype," and "FaceTime") were mentioned by 33\% $(N=252)$, The use of digital communication mainly involved activities such as attending online religious services (EN_UK_0412); talking to friends and family (EN_UK_0418, EN_MX_0545; EN_JP_0018); online exercise classes, seminars, and conference attendance (EN_OO_0088); remote working (EN_UK_0026); and home school purposes (EN_UK_0165).

\subsection{Notions of Time}

Temporality is a central feature of human experience, and we were interested in how participants experienced time. This topic elicited a lot of responses; "time" was mentioned by $73 \%$ of UK participants $(N=551)$. How time was impacted varied between participants. Some participants reported no change of time experience, while others noted changes. In the latter case, there seem to be two distinctive kinds of changes: either people lost their sense of the flow of time, for instance due to boredom (references to "boredom,", "boring," "bore" were made by $8 \%$ of UK participants $(N=62)$, see e.g., EN_UK_0038, EN_MX_0026), or they experienced a more rapid flow of time because they were becoming more productive. For example, one participant mentioned a sense of gaining time because they no longer had to commute to work (EN_OO_0542).

\subsection{Coping Mechanisms}

Participants mentioned coping with crisis and maintaining well-being by engaging in activities such as yoga (UK_EN_0032), meditation (UK_EN_0047), mindfulness (UK_EN_0291), running and cycling (EN_OO_1515), walking the dog (UK_EN_ 0058). Some also report reading books (EN_MX_0619), returning to old hobbies (EN_JP_0309) or starting new ones (EN_JP_2238), talking to friends and family (EN_JP_0623), and spending more time with their families. Finally, many participants reported exercising more, although others had to deal with exercising less.

\subsection{Interpersonal Relationships}

Some participants noted that their sense of trusting others had not changed (EN_UK_0013, EN_MX_ 0573). But other participants reported that trusting neighbors and people in general was now an issue (EN_MX_0663), for instance not trusting others to follow social distancing rules (walking in the street or queuing in the supermarket). There was also notable mistrust in news media and a lack of trust in government decisions (EN_UK_0039). In addition, some people reported a lack of interpersonal contact, which expressed itself as loneliness and sadness (EN_UK_0253; EN_UK_0412).

\subsection{Experiencing Grief}

The section on grief was not concerned specifically with COVID-related bereavements during the pandemic, but with bereavements more generally. The survey was conducted during the early stages of the pandemic, therefore comparatively few people had been experiencing grief due to someone dying of COVID-19 (but see EN_UK_0371). Grief in relation to death was accompanied with a sense of frustration about being unable to travel and attending funerals (UK_EN_0356), and thus there were reports of experiencing grief in isolation instead of as a family process (UK_EN_0027). Other types of grief mentioned were grieving the consequences of the pandemic, especially the inability to meet relatives or friends (UK_EN_0081). Also, there was grief for life before the pandemic, as well as a sense of loss of direction, of meaning, and of opportunities (EN_JP_0298).

\subsection{Future Hopes}

In general terms, participants often thought about future hopes as a return to normality (UK_EN_0050). Many hoped for the arrival of a vaccine (references to "vaccine" or "vaccination" were made by $15 \%$ of UK participants, $N=116$ ). Others referred to desiring to travel and visit family and friends (UK_EN_0044). Parents mentioned wishing a promising future for their children (EN_JP_0300). Some participants also referred to learning how to be kind to others and exercise positive behavior and human skills (EN_JP_0737). Finally, participants also hoped for political and economic change (UK_EN_0019).

\section{FUTURE DIRECTIONS}

We are in the process of analysing the corpus using both quantitative and qualitative methods. As a first pass, we are using computational techniques to automatically analyze the written text (also known as "natural language processing" techniques) to provide an overall assessment of language use and valence. On this basis we will select particularly illustrative case studies to guide a deeper phenomenological interpretation of the subjective experience of the pandemic. The novelty of this research approach is that we are thereby integrating methods from the social and computer sciences, allowing us to scale up phenomenological analysis of subjective experience to a large sample. Of particular interest is the cross-cultural aspect of the corpus: this allows investigators to compare whether certain kinds of experiences of the pandemic are shared across cultures, or whether they are context-specific.

The current corpus provides a record of subjective reports for a 2-month period in 2020 when the UK, Japan, and Mexico started to relax the more severe social distancing measures that were in place during the first wave of the pandemic. Now, over a year later, we are undergoing another important transition, as vaccines have started to be administered in these countries. In order to get a sense for the current state of the pandemic experience, we have re-launched the survey for the 1,026 participants who had agreed to be contacted about future studies. We plan to publish the responses we are collecting in future work as another publicly available corpus. This will enable researchers 
to also perform longitudinal analyses of people's responses, comparing their experience after the initial wave of the pandemic with their experience after the onset of vaccination programs. Given that some systematic reviews of the psychological impact have found minimal effects on symptoms of mental illness (22), and others highlight that most people are psychologically resilient to the effects of lockdowns (6), it will be particularly interesting to take a closer look at the conditions that enabled this resilience. We expect that this will uncover important insights into the nature of human flourishing, even under adverse conditions.

\section{DATA AVAILABILITY STATEMENT}

The datasets presented in this study can be found in a Figshare online repository (doi: 10.6084/m9.figshare.15060138) at the following link: https://figshare.com/articles/dataset/_/15060138.

\section{ETHICS STATEMENT}

The studies involving human participants were reviewed and approved by Human Subjects Research Review Committee (HSRRC), Okinawa Institute of Science and Technology Graduate University (OIST). The patients/participants

\section{REFERENCES}

1. Carel H, Ratcliffe M, Froese T. Reflecting on experiences of social distancing. Lancet. (2020) 396:87-8. doi: 10.1016/S0140-6736(20)31485-9

2. Xiong J, Lipsitz O, Nasri F, Lui LM, Gill H, Phan L, et al. Impact of COVID-19 pandemic on mental health in the general population: a systematic review. $J$ Affect Disord. (2020) 277:55-64. doi: 10.1016/j.jad.2020.08.001

3. Salari N, Hosseinian-Far A, Jalali R, Vaisi-Raygani A, Rasoulpoor S, Mohammadi M, et al. Prevalence of stress, anxiety, depression among the general population during the COVID-19 pandemic: a systematic review and meta-analysis. Global Health. (2020) 16:57. doi: 10.1186/s12992-020-00589-w

4. Rubin GJ, Wessely S. The psychological effects of quarantining a city. BMJ. (2020) 368:m313. doi: 10.1136/bmj.m313

5. Lee S, Neimeyer R. Pandemic Grief Scale: A screening tool for dysfunctional grief due to a COVID-19 loss. Death Stud. (2020). doi: 10.1080/07481187.2020.1853885. [Epub ahead of print].

6. Prati G, Mancini AD. The psychological impact of COVID-19 pandemic lockdowns: a review and meta-analysis of longitudinal studies and natural experiments. Psychol Med. (2021) 51:201-11. doi: $10.1017 /$ S0033291721000015

7. Dimmock J, Krause AE, Rebar A, Jackson B. Relationships between social interactions, basic psychological needs, and wellbeing during the COVID19 pandemic. Psychol Health. (2021). doi: 10.1080/08870446.2021.1921178. [Epub ahead of print].

8. Spinney L. What are COVID archivists keeping for tomorrow's historians? Nature. (2020) 588:578-80. doi: 10.1038/d41586-020-03554-0

9. Kobayashi LC, O'Shea BQ, Kler JS. Cohort profile: the COVID-19 coping study, a longitudinal mixed-methods study of middle-aged and older adults' mental health and well-being during the COVID-19 pandemic in the USA. BMJ Open. (2021) 11:e044965. doi: 10.1136/bmjopen-2020-044965

10. Ruiz MC, Devonport TJ, Chen-Wilson CHJ, Nicholls W, Cagas JY, Fernandez-Montalvo J, et al. A cross-cultural exploratory study of health behaviors and wellbeing during COVID-19. Front Psychol. (2021) 11:608216. doi: $10.3389 /$ fpsyg.2020.608216 provided their written informed consent to participate in this study.

\section{AUTHOR CONTRIBUTIONS}

TF and MR initiated the project. TF, TM, MR, HC, AM, MB, $\mathrm{CH}$, and FS contributed to the design of this study, including defining the questionnaire, and data collection. FS implemented the questionnaire as an online survey, managed participant recruitment, extracted the corpus, and performed initial natural language processing and statistical analyses. JR performed the initial data coding. TF and JR wrote the first draft of the manuscript. All authors reviewed and finalized the manuscript.

\section{FUNDING}

This work was supported by JSPS Topic Setting Program to Advance Cutting Edge Humanities and Social Sciences Research (Grant Number JPJS00120350377).

\section{ACKNOWLEDGMENTS}

We thank Mark James for stimulating discussions. We thank Akash Kulgod for preparing the figures and tables.

11. Travaglino GA, Moon C. Compliance and self-reporting during the COVID19 pandemic: a cross-cultural study of trust and self-conscious emotions in the United States, Italy, and South Korea. Front Psychol. (2021) 12:565845. doi: $10.3389 /$ fpsyg. 2021.565845

12. von Humboldt S, Mendoza-Ruvalcaba NM, Arias-Merino ED, Costa A, Cabras E, Low G, et al. Smart technology and the meaning in life of older adults during the Covid-19 public health emergency period: a cross-cultural qualitative study. Int Rev Psychiatry. (2020) 32:713-22. doi: 10.1080/09540261.2020.1810643

13. Ratcliffe M. Experiences of Depression: A Study in Phenomenology. Oxford: Oxford University Press (2014).

14. Carel H. Phenomenology of Illness. Oxford: Oxford University Press (2016). doi: 10.1093/acprof:oso/9780199669653.001.0001

15. Froese T. Searching for the conditions of genuine intersubjectivity: from agent-based models to perceptual crossing experiments. In: Newen A, De Bruin L, Gallagher S, editors. The Oxford Handbook of $4 E$ Cognition. Oxford: Oxford University Press (2018). p. 163-86. doi: 10.1093/oxfordhb/9780198735410.013.9

16. Malpass A, Dodd J, Feder G, Macnaughton J, Rose A, Walker O, et al. Disrupted breath, songlines of breathlessness: an interdisciplinary response. Med Human. (2019) 45:294-303. doi: 10.1136/medhum-2018-0 11631

17. Hofstede G. Culture's Consequences: Comparing Values, Behaviors, Institutions and Organizations Across Nations. Sage Publications (2001).

18. Ritchie H, Ortiz-Ospina E, Beltekian D, Mathieu E, Hasell J, Macdonald B, et al. Coronavirus Pandemic (COVID-19). Our World in Data (2020). Available online at: https://ourworldindata.org/coronavirus (accessed July 07, 2021).

19. Office for National Statistics. People, Population and Community. (2020). Available online at: https://www.ons.gov.uk/peoplepopulationandcommunity (accessed July 07, 2021).

20. National Institute of Statistics and Geography: Censo de Poblacin y Vivienda. (2020). Available online at: https://www.inegi.org.mx/programas/ccpv/2020/\# (accessed July 07, 2021). 
21. Statistics Bureua of Japan: Population Report. (2021). Available online at: http://www.stat.go.jp/english/data/jinsui/tsuki/index.html (accessed on 07/07/2021).

22. Rogers JP, Chesney E, Oliver D, Pollak TA, McGuire P, FusarPoli P, et al. Psychiatric and neuropsychiatric presentations associated with severe coronavirus infections: a systematic review and meta-analysis with comparison to the COVID-19 pandemic. Lancet Psychiatry. (2020) 7:611-27. doi: 10.1016/S2215-0366(20)3 0203-0

Conflict of Interest: The authors declare that the research was conducted in the absence of any commercial or financial relationships that could be construed as a potential conflict of interest.
Publisher's Note: All claims expressed in this article are solely those of the authors and do not necessarily represent those of their affiliated organizations, or those of the publisher, the editors and the reviewers. Any product that may be evaluated in this article, or claim that may be made by its manufacturer, is not guaranteed or endorsed by the publisher.

Copyright (c) 2021 Froese, Broome, Carel, Humpston, Malpass, Mori, Ratcliffe, Rodrigues and Sangati. This is an open-access article distributed under the terms of the Creative Commons Attribution License (CC BY). The use, distribution or reproduction in other forums is permitted, provided the original author $(s)$ and the copyright owner(s) are credited and that the original publication in this journal is cited, in accordance with accepted academic practice. No use, distribution or reproduction is permitted which does not comply with these terms. 